\title{
GESTÃO ESCOLAR E AS NOVAS INCUMBÊNCIAS IMPOSTAS PELA LEI FEDERAL $N^{\circ} 13.663 / 18$
}

\section{LÚCIO JORGE HAMMES}

Universidade Federal do Pampa (UNIPAMPA). Doutor em Educação (Universidade do Vale do Rio dos Sinos). Mestre em Teologia (Pontifícia Universidade Católica do Rio Grande do Sul). Graduação em Filosofia (Faculdade de Filosofia N Sa da Imaculada Conceição 1988) e em Teologia (Pontifícia Universidade Católica do Rio Grande do Sul). Professor Associado da Universidade Federal do Pampa. ORCID: 0000-0003-0658-4628. E-mail: luciojh@gmail.com

\footnotetext{
ALEXANDRE ZACARIA SEBAJE

Universidade Federal do Pampa (UNIPAMPA). Mestre em Educação (Unipampa). Graduação em Letras com habilitação em Português/Inglês (1999), Direito (2012) e Educação Física (2017). Especialista em Direito Penal e Processual Penal, com capacitação para o Ensino do Magistério Superior. Professor da Rede Pública do Estado-RS. Vice-diretor na Escola Técnica Estadual João XXIII. ORCID: 0000-0002-6360-6603 E-mail: azsebaje@gmail.com
} 


\section{GESTÃO ESCOLAR E AS NOVAS INCUMBÊNCIAS IMPOSTAS PELA LEI FEDERAL No ${ }^{\circ}$ 13.663/18}

A presente pesquisa, centrada teoricamente na área da Educação, compreende uma investigação de abordagem qualitativa, cujo escopo abrange questões pertinentes a Lei Federal $n^{\circ}$ 13.663/18 que acrescentou os incisos IX e X ao Art. 12 da Lei de Diretrizes e Bases da Educação (BRASIL, 2018). Tais incisos obrigam os envolvidos no processo de ensino e aprendizagem a promoverem medidas de conscientização, de prevenção e de combate a todos os tipos de violência, bem como estabelecerem ações destinadas à promoção da cultura de paz no âmbito escolar. A pesquisa tem como objetivo contribuir para o debate e a percepção dos gestores escolares no que se refere às novas incumbências impostas pela lei em questão. O lócus da investigação é uma escola de Ensino Médio de Pelotas pertencente à Rede Pública Estadual de Ensino do Estado do Rio Grande do Sul. O corpus analítico emerge de dados obtidos por meio de dois questionários com perguntas abertas, destacando-se a análise de conteúdo como método precípuo de tratamento dos dados.. Os resultados obtidos indicam a necessidade de qualificar os gestores em educação para que possam, assim, colocar efetivamente em prática as novas disposições. Sugere-se, assim, a inclusão de cursos de formação e capacitação de gestores, a fim de inspirar novas e potentes discussões e construções de saberes acerca das novas diretrizes.

Palavras-chave: Cultura de paz, Conflito, Mediação de conflito, Gestão escolar.

\section{SCHOOL MANAGEMENT AND THE NEW INCUMBENCIES IMPOSED BY THE LAW $\mathrm{N}^{0} \mathbf{1 3 . 6 6 3 / 1 8}$}

The present research, theoretically centered in the field of Education, comprises a qualitative approach investigation, whose scope covers issues concerning the Federal Law n. 13.663/18 which added the subparagraphs IX and X to Art. 12 of the Law of Directives and Bases of Education (BRAZIL, 2018). Such subparagraphs compel the involved parties in the teaching and learning process to foster awareness-raising, prevention and combat measures related to all types of violence as well as set actions to foster the culture of peace in the school environment. The research aims at contributing for the debate and the perception of the school managers concerning the new responsibilities imposed by the law in question. The locus of the investigation is a High School in Pelotas belonging to the State Public Network of Education of the State of Rio Grande do Sul. The analytical corpus arises from the obtained data through two questionnaires with open questions, highlighting the analysis of content as the main method to deal with the data. The results obtained indicate the need of qualifying the managers so that they can, thus, put into practice the new provisions. It is then suggested the inclusion of school managers training courses in order to new and powerful discussions and the construction of knowledge about the new directives.

Keywords: Culture of peace, Conflict, Mediation of conflict, School management.

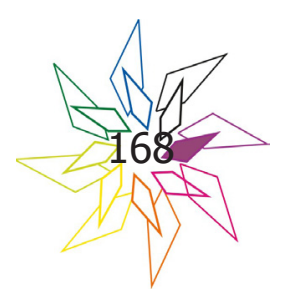




\section{GESTIÓN ESCOLAR Y LAS NUEVOS DEBERES IMPUESTOS POR LA LEY FEDERAL $N^{\circ}$ 13.663/18}

La presente investigación, teóricamente centrada en el área de Educación, comprende una investigación de enfoque cualitativo, cuyo objetivo abarca temas pertinentes a la Ley Federal $n^{\circ}$ 13.663/18 que agregó los ítems IX y X al Art. 12 de la Ley de Directrices y Bases de Educación ( BRASIL, 2018). Tales ítems obligan a los involucrados en el proceso de enseñanza y aprendizaje a promover medidas de concientización, de prevención y de combate a todos tipos de violencia, así como establecer acciones destinadas a la promoción de la cultura de paz en el entorno escolar. El objetivo de la investigación es contribuir al debate y la percepción de los gestores escolares sobre las nuevas tareas impuestas por la ley en cuestión. El foco de la investigación es una escuela secundaria en Pelotas que pertenece a la Red de Educación Pública del Estado del Estado de Rio Grande do Sul. El corpus analítico surge de los datos obtenidos a través de dos cuestionarios con preguntas abiertas, destacando el análisis de contenido como un método fundamental de procesamiento de los datos. Los resultados obtenidos indican la necesidad de calificarlos para que puedan poner en práctica las nuevas disposiciones. Se sugiere, por lo tanto, la inclusión de cursos de formación y capacitación de gestores, con el fin de inspirar nuevos y potentes debates y construcciones de saberes sobre las nuevas directrices.

Palabras clave: Cultura de paz, Conflicto, Mediación de conflicto, Gestión escolar. 


\section{GESTÃO ESCOLAR E AS NOVAS INCUMBÊNCIAS IMPOSTAS PELA LEI FEDERAL $N^{\circ} \mathbf{1 3 . 6 6 3 / 1 8}$}

\section{Introdução}

A Lei Federal $n^{\circ}$ 13.663/18 introduziu os incisos IX e X ao Art. 12 da Lei de Diretrizes e Bases da Educação (BRASIL, 2018). Com os novos dispositivos os estabelecimentos de ensino passaram, também, a ter a incumbência de estabelecer ações destinadas a promover a cultura de paz e medidas de conscientização, de prevenção e combate a todos os tipos de violência.

Art. $1^{\circ}$ - O caput do art. 12 da Lei $n^{\circ} 9.394$, de 20 de dezembro de 1996, passa a vigorar acrescido dos seguintes incisos:

Art. $12^{\circ}-(\ldots)$

IX - promover medidas de conscientização, de prevenção e de combate a todos os tipos de violência, especialmente a intimidação sistemática (bullying), no âmbito das escolas;

$\mathrm{X}$ - estabelecer ações destinadas a promover a cultura de paz nas escolas. (BRASIL, 2018, p.1)

Frente a este novo contexto é relevante que os gestores educacionais tenham conhecimento em relação ao exposto nos dispositivos mencionados na nova lei para que possam, assim, colocá-los em prática. Com foco nesta nova base normativo surge a seguinte indagação: "Até que ponto o gestor escolar é detentor do conhecimento exposto nos dispositivos acrescentados pela Lei Federal no 13.663/18?".

Para tentar responder o questionamento acima, realizamos um estudo preliminar/diagnóstico junto à escola foco da presente pesquisa. $\mathrm{O}$ diagnóstico teve como mote investigativo as seguintes indagações: a) Você já ouviu falar a respeito de Cultura de Paz? O que você entende da mesma? b) O que você entende por conflito? c) O que você entende por mediação de conflito?

Os resultados do estudo preliminar demonstraram que os participantes, um diretor e dois vice-diretores, desconhecem os conceitos de "Cultura de Paz, Conflito e Mediação". Definições estas importantes para que se possam colocar em prática as disposições impostas pela nova lei.

\footnotetext{
plurais

Salvador, v. 5, n.3, p. 167-182, set./dez. 2020
} 
Portanto, a partir do diagnóstico obtido traçou-se a presente pesquisa que tem como objetivo principal contribuir para o debate e a percepção dos gestores escolares no que se refere às novas incumbências impostas pela lei e, como secundários, investigar a efetividade da nova lei e averiguar a percepção dos sujeitos da pesquisa no que se refere à Cultura de Paz, ao Conflito e à Mediação de Conflito.

Para tanto, realizamos uma intervenção junto a uma escola estadual de ensino médio de Pelotas/RS. Os participantes da pesquisa foram quatorze alunos do primeiro ano do ensino médio da referida escola. Os dados do presente estudo foram levantados a partir de um relatório crítico-reflexivo, de autoria de Sebaje (2020), submetido e aprovado pela banca examinadora, como requisito para o título de Mestre em Educação, do Programa de Pós-graduação em Educação do Curso de Mestrado Profissional em Educação da Unipampa - Campus Jaguarão/RS.

Como referenciais teóricos norteadores da presente investigação utilizamos, dentre outros, Callado (2004) no que se refere à "Cultura de Paz”, Chrispino (2002) e Guimarães (2005) no que concerne ao "Conflito" e, por fim, Garcez (2003) e Novaes (2012) em relação a "Mediação de Conflitos". Os referenciais serão abordados e explorados na seção tocante aos resultados e discussões.

Após a introdução, o artigo traz a delimitação metodológica com a fundamentação dos caminhos da pesquisa que serão tratados com a perspectiva da análise de conteúdo. Posteriormente traz os resultados e as discussões e, por fim, apresenta as considerações finais e as referências utilizadas.

\section{Metodologia}

A pesquisa tem como objetivo principal, como já mencionado, contribuir para o debate e a percepção dos gestores escolares no que se refere às novas incumbências impostas pela lei em questão. O lócus da investigação é uma escola de Ensino Médio de Pelotas pertencente à Rede Pública Estadual de Ensino do Estado do Rio Grande do Sul/Brasil.

O educandário em questão é a Escola de Ensino Médio Dr. Amilcar Gigante localizado na periferia de Pelotas/RS. A escola fica situada entre três bairros: Eldorado, Pestano e Getúlio Vargas. Cabe mencionar que a escola é a única de Ensino Médio na localidade. Dessa forma, atende, em sua maioria, alunos oriundos dos bairros citados.

\section{plurais}


A população do estudo são 14 alunos, com idades entre 17 e 34 anos, do primeiro ano de ensino médio noturno. Os sujeitos participantes foram selecionados para fazerem parte da pesquisa por pertencerem à turma, de acordo com a direção da escola, de maior incidência de conflitos, bem como por meio de uma exposição oral por parte do pesquisador a respeito da intervenção.

A intervenção foi realizada no segundo semestre de 2019 e se deu por meio de quatro encontros presenciais. Nos mesmos, o pesquisador colocou em prática os dispositivos da nova lei, ou seja, buscou promover a Cultura de Paz, bem como trabalhar, por meio da Mediação Pacífica de Conflito, com a conscientização, a prevenção e o combate à violência. Dessa forma, durante as intervenções foram discutidas as diversas formas de violência, a diferença entre os conceitos de violência e conflito e as bases da Cultura de Paz. Também, foi possível vivenciar a Mediação Pacífica de Conflitos por meio de simulações de casos conflitantes nos quais os participantes da pesquisam puderam atuar com mediadores.

Os dados foram coletados através de dois questionários com perguntas abertas, um respondido no início e o outro ao término da intervenção. A seguir, os mesmos foram categorizados com base na pertinência e na adequação em relação aos objetivos da pesquisa. Para Moraes (1999) a categorização:

É um procedimento de agrupar dados considerando a parte comum existente entre eles. Classifica-se por semelhança ou analogia, segundo critérios previamente estabelecidos ou definidos no processo. Estes critérios podem ser semânticos, originando categorias temáticas. Podem ser sintáticos definindose categorias a partir de verbos, adjetivos, substantivos, etc. As categorias podem ainda ser constituídas a partir de critérios léxicos, com ênfase nas palavras e seus sentidos ou podem ser fundadas em critérios expressivos focalizando em problemas de linguagem. Cada conjunto de categorias, entretanto, deve fundamentar-se em apenas um destes critérios (MORAES, 1999, p. 06).

Dessa forma, o presente estudo tem uma abordagem metodológica qualitativa a partir de dois questionários com perguntas abertas a respeito da Cultura de Paz, do Conflito e da Mediação de Conflitos. No intuito de contemplar o objetivo da presente pesquisa, elegeu-se a referida abordagem para o desenvolvimento da presente pesquisa, a qual, segundo Minayo (1994): 
(...) responde a questões muito particulares. Ela se preocupa, nas ciências sociais, com um nível de realidade que não pode ser quantificado. Ou seja, ela trabalha com o universo de significados, motivos, aspirações, crenças, valores e atitudes, o que corresponde a um espaço mais profundo das relações, dos processos e dos fenômenos que não podem ser reduzidos à operacionalização de variáveis. (MINAYO 1994, p. 21-22)

O questionário pode ser definido, segundo Gil (2008), como a técnica de investigação composta por um número mais ou menos elevado de questões apresentadas por escrito às pessoas, tendo por objetivo o conhecimento de opiniões, crenças, sentimentos, interesses, expectativas, situações e etc.

Sendo assim, podemos afirmar que o presente estudo se caracteriza como uma pesquisa qualitativa, a qual se utilizou da análise de conteúdo como metodologia precípua de tratamento dos dados, por entender que esta se fundamenta como um guia para conduzir o estudo que aqui se investiga.

Conforme Bardin (2011, p.44) a metodologia análise de conteúdo consiste em "um conjunto de técnicas de análise das comunicações que utiliza procedimentos sistemáticos e objetivos de descrição do conteúdo das mensagens e que tem como finalidade a realização de inferências".

Cabe frisar que a análise de conteúdo, em sua vertente qualitativa, parte de uma série de pressupostos, os quais, no exame de um texto, servem de suporte para captar seu sentido simbólico. Dessa forma, foi importante categorizar esses dados.

\section{Resultados e Discussões}

De posse dos dados coletados, por meio dos instrumentos já citados, passamos a categorização das unidades de análise. A intenção foi investigar a efetividade da lei e verificar se houve evolução na percepção dos participantes em relação aos conceitos de Cultura de Paz, Conflito e Mediação de Conflito. Dessa forma, foram criadas três categorias com os respectivos indicadores. Na categoria "Cultura de Paz" os indicadores foram criados com base em Callado (2004, p.28). 
Quadro 1 - Comparativo entre Cultura de Paz e Cultura Tradicional conforme Callado (2004)

\begin{tabular}{|l|l|}
\hline \multicolumn{1}{|c|}{ Cultura Tradicional (Paz Negativa) } & \multicolumn{1}{c|}{ Cultura de Paz (Paz Positiva) } \\
\hline $\begin{array}{l}\text { Paz definida como ausência de guerras e violência di- } \\
\text { reta. }\end{array}$ & $\begin{array}{l}\text { Paz definida como ausência de todo tipo de } \\
\text { violência (direta ou estrutural) e como pre- } \\
\text { sença de justiça social. }\end{array}$ \\
\hline $\begin{array}{l}\text { Paz limitada as relações nacionais e internacionais, cuja } \\
\text { manutenção depende dos Estados. }\end{array}$ & $\begin{array}{l}\text { Paz abrange todos os âmbitos da vida, incluí- } \\
\text { dos o pessoal e o interpessoal. A responsabili- } \\
\text { dade é de todos. }\end{array}$ \\
\hline $\begin{array}{l}\text { Paz como um fim, uma meta a que se tende e que nunca } \\
\text { se alcança plenamente. }\end{array}$ & Paz como processo contínuo e permanente. \\
\hline $\begin{array}{l}\text { O fim justifica os meios, podendo-se justificar a violên- } \\
\text { cia para garantir a paz. }\end{array}$ & $\begin{array}{l}\text { Os meios não justificam os fins, assim como a } \\
\text { violência não é considerada um meio para se } \\
\text { alcançar a paz. }\end{array}$ \\
\hline $\begin{array}{l}\text { Paz como ideal utópico e inalcançável, depende de } \\
\text { fatores externos a ela. }\end{array}$ & $\begin{array}{l}\text { Paz como processo contínuo e acessível por } \\
\text { meio de ações de cooperação, mútuo enten- } \\
\text { dimento, dentre outras posturas que assentam } \\
\text { as bases das relações interpessoais e intergru- } \\
\text { pais. }\end{array}$ \\
\hline Conflito concebido como algo negativo. & $\begin{array}{l}\text { A forma de regular o conflito torna a situação } \\
\text { positiva (mediação/regulação) ou negativa } \\
\text { (violência). }\end{array}$ \\
\hline Conflitos devem ser evitados. & $\begin{array}{l}\text { Conflitos devem ser manifestados e regula- } \\
\text { dos, sem se recorrer à violência (ação pacífi- } \\
\text { ca). }\end{array}$ \\
\hline
\end{tabular}

Fonte: Callado, 2004, p.28

Também, utilizamos como indicador da categoria "Cultura de Paz" o conceito dado pela Organização das Nações Unidas (ONU).

Uma Cultura de Paz é um conjunto de valores, atitudes, tradições, comportamentos e estilos de vida baseados: No respeito à vida, no fim da violência e na promoção e prática da não violência por meio da educação, do diálogo e da cooperação; No pleno respeito e na promoção de todos os direitos humanos e liberdades fundamentais; No compromisso com a solução pacífica dos conflitos; Nos esforços para satisfazer as necessidades de desenvolvimento e proteção do meio-ambiente para as gerações presentes e futuras; No respeito e fomento à igualdade de direitos e oportunidades de mulheres e homens; No 
respeito e fomento ao direito de todas as pessoas à liberdade de expressão, opinião e informação; $\mathrm{Na}$ adesão aos princípios de liberdade, justiça, democracia, tolerância, solidariedade, cooperação, pluralismo, diversidade cultural, diálogo e entendimento em todos os níveis da sociedade e entre as nações; e animados por uma atmosfera nacional e internacional que favoreça a paz (ONU, 1999, p.2-3).

Desta forma, partimos da compreensão de que Cultura de Paz é um conjunto de valores baseados, dentre outros, no respeito à vida, no fim da violência e na promoção e prática da não violência por meio da educação e do diálogo. Dessa forma, Cultura de Paz só é possível com a presença de justiça social, solidariedade, cooperação e respeito.

Para a análise da categoria "Conflito" foram elaborados os indicadores a partir das definições de Chrispino (2002) e Guimarães (2005):

Conflito é toda opinião divergente ou maneira diferente de ver ou interpretar algum acontecimento. A partir disso, todos os que vivemos em sociedade temos a experiência do conflito. Desde os conflitos próprios da infância, passamos pelos conflitos pessoais da adolescência e, hoje, visitados pela maturidade, continuamos a conviver com o conflito intrapessoal (...) ou interpessoal. (CHRISPINO; CHRISPINO, 2002, p. 16)

O conflito é um elemento conatural da vida pessoal; não é necessariamente negativo, dependendo do modo como é enfrentado, gerido e resolvido, seguramente causa sofrimento, mas pode ser ocasião de crescimento e mudança, pessoal e coletiva. Para isso é necessário reconhecer os conflitos e não removê-los, ou fazê-los emergir, quando são latentes, mas constituem um problema real ao menos para uma das partes. Também a paz não é ausência de conflitos, nem apenas ausência de guerra, mas ausência da violência em todas as suas formas (PACE e DINTORNI apud GUIMARÃES, 2005, p. 70).

Partimos da compreensão de conflito como toda opinião divergente, natural e inerente ao homem. Além disso, pode ser positivo ou negativo conforme o seu tratamento. Se levar a violência será sempre negativo, se levar ao crescimento pessoal e/ou social torna-se positivo.

Por fim, os indicadores referentes à categoria "Mediação de Conflitos" partiram, dentre outros, de Garcez (2003, p. 35), que afirma que a mediação é uma solução de conflitos na qual um terceiro de maneira imparcial auxilia as partes a chegarem a um acordo entre si. Também, foi utilizado Novaes (2012) que afirma: 
A mediação baseia-se na arte da linguagem para permitir a criação ou recriação da relação. Implica a intervenção de um terceiro neutro, imparcial e independente, o mediador que desempenha uma função de intermediário nas relações. Em resumo, o mediador operacionaliza a qualidade da relação e da comunicação entre as partes cujos interesses divergem a ponto de instaurar-se uma situação litigiosa (NOVAES, 2012, p. 4).

Dessa forma, passamos, a seguir, as análises dos instrumentos com bases nas categorias e indicadores mencionados.

Quadro 2 - Descrição quantitativa das ocorrências, Questionário Inicial, relacionadas à categoria "Cultura de Paz" e seus respectivos indicadores

\begin{tabular}{|c|l|c|}
\hline $\begin{array}{c}\text { Categoria 1: } \\
\text { "Cultura de Paz" }\end{array}$ & \multicolumn{1}{|c|}{ Indicadores } & Alunos (14) \\
\hline Conhece & $\begin{array}{l}\text { - Presença de justiça social, solidariedade, cooperação } \\
\text { e respeito. } \\
\text { - Solução pacífica dos conflitos. }\end{array}$ & - \\
\hline Desconhece & - Uso do advérbio de negação & 13 \\
\hline Conhece em parte & $\begin{array}{l}\text { - Evitar conflitos. } \\
\text { - Não violência }\end{array}$ & 01 \\
\hline TOTAL & & 14 \\
\hline
\end{tabular}

Fonte: Elaborado para esta análise a partir da pesquisa desenvolvida na escola.

Quadro 3 - Descrição quantitativa das ocorrências, Questionário Final, relacionadas à categoria "Cultura de Paz" e seus respectivos indicadores

\begin{tabular}{|c|l|c|}
\hline $\begin{array}{c}\text { Categoria 1: "Cultu- } \\
\text { ra de Paz" }\end{array}$ & \multicolumn{1}{|c|}{ Indicadores } & Alunos (14) \\
\hline Conhece & $\begin{array}{l}\text { - Presença de justiça social, solidariedade, cooperação, } \\
\text { igualdade e respeito. } \\
\text { - Solução pacífica dos conflitos. }\end{array}$ & 10 \\
\hline Desconhece & $\begin{array}{l}\text { - Uso do advérbio de negação (não). } \\
\text { - Uso do advérbio de tempo (nunca, jamais). }\end{array}$ & 01 \\
\hline Conhece em parte & $\begin{array}{l}\text { - Evitar conflitos. } \\
\text { - Não violência }\end{array}$ & 03 \\
\hline TOTAL & & 14 \\
\hline
\end{tabular}

Fonte: Elaborado para esta análise a partir da pesquisa desenvolvida na escola. 
Os dados do o Quadro 2, em relação a categoria "Cultura de Paz", mostram que nenhum dos participantes tinha conhecimento em relação ao conceito e apenas um o conhecia em parte. O advérbio de negação (não) teve treze ocorrências. No entanto, após a intervenção, quadro 3, dez sujeitos expressaram conhecimento em relação à Cultura de Paz. Os indicadores que mais apareceram nas respostas foram: cultura de igualdade, de respeito e presença de justiça social.

Dessa forma, constatamos que houve aquisição de aprendizagem e aumento de percepção dos sujeitos em relação à categoria, visto que há nas respostas a presença da justiça social, a não violência e o respeito à diversidade. Respostas estas que estão de acordo com o conceito dado pela ONU.

Quadro 4 - Descrição quantitativa das ocorrências, Questionário Inicial, relacionadas à categoria "Conflito" e seus respectivos indicadores

\begin{tabular}{|c|l|c|}
\hline $\begin{array}{c}\text { Categoria 2: } \\
\text { "Conflito" }\end{array}$ & \multicolumn{1}{|c|}{ Indicadores } & Alunos (14) \\
\hline Conhece & - Inerente e natural. & -- \\
\hline - Positivo e negativo. & 04 \\
\hline Desconhece & - Uso do advérbio de negação & 10 \\
\hline TOTAL & & 14 \\
\hline
\end{tabular}

Fonte: Elaborado para esta análise a partir da pesquisa desenvolvida na escola.

Quadro 5 - Descrição quantitativa das ocorrências, Questionário Final, relacionadas à categoria "Conflito" e seus respectivos indicadores

\begin{tabular}{|l|l|l|}
\hline \multicolumn{1}{|c|}{ Categoria 2: "Conflito" } & \multicolumn{1}{c|}{ Indicadores } & \multicolumn{1}{c|}{ Alunos (14) } \\
\hline Conhece & $\begin{array}{l}\text { - Inerente e natural. } \\
\text { - Positivo e negativo. }\end{array}$ & 09 \\
\hline Desconhece & - Uso do advérbio de negação & -- \\
\hline Conhece em parte & $\begin{array}{l}\text { - Ocorrências de léxicos como: violência, } \\
\text { briga, discórdia, discussão e agressão. }\end{array}$ & 05 \\
\hline TOTAL & & 14 \\
\hline
\end{tabular}

Fonte: Elaborado para esta análise a partir da pesquisa desenvolvida na escola.

\section{plurais}


No que se refere à categoria "Conflito" constatamos, conforme quadro 4 , que 10 sujeitos conheciam em parte o significado do vocábulo, visto que citaram apenas o sentido negativo do léxico, ou seja, como sinônimo de violência. No entanto, de acordo com o quadro 5, nove dos participantes demonstraram ter adquirido aprendizado após a intervenção.

Percebemos, portanto, que após a intervenção grande parte dos participantes passou a ver conflito como algo tanto negativo quanto positivo e perceberam, ainda, que dependendo do modo como é enfrentado pode trazer crescimento pessoal e coletivo.

Quadro 6 - Descrição quantitativa das ocorrências, Questionário Inicial, relacionadas à categoria "Mediação de Conflito" e seus respectivos indicadores

\begin{tabular}{|c|l|c|}
\hline $\begin{array}{c}\text { Categoria 3 } \\
\text { "Mediação de Conflito" }\end{array}$ & \multicolumn{1}{|c|}{ Indicadores } & Alunos (14) \\
\hline Conhece & $\begin{array}{l}\text { - Meio de Solução/resolução de conflitos. } \\
\text { - Terceira pessoa facilita a resolução. } \\
\text { - Imparcialidade. }\end{array}$ & -- \\
\hline Desconhece & - Uso do advérbio de negação. & 14 \\
\hline Conhece em parte & - Solução/resolução de conflitos. \\
& - Uso do verbo "fazer, interromper e impedir". & -- \\
\hline TOTAL & & 14 \\
\hline
\end{tabular}

Fonte: Elaborado para esta análise a partir da pesquisa desenvolvida na escola.

Quadro 7 - Descrição quantitativa das ocorrências, Questionário Final, relacionadas à categoria "Mediação de Conflito" e seus respectivos indicadores

\begin{tabular}{|l|l|l|}
\hline $\begin{array}{l}\text { Categoria 3 } \\
\text { "Mediação de Conflito" }\end{array}$ & Indicadores & Alunos (14) \\
\hline Conhece & $\begin{array}{l}\text { - Meio de Solução/resolução de conflitos. } \\
\text { - Terceira pessoa facilita a resolução. } \\
\text { - Imparcialidade. }\end{array}$ & 07 \\
\hline Desconhece & - Uso do advérbio de negação. & -- \\
\hline Conhece em parte & $\begin{array}{l}\text { - Solução/resolução de conflitos. } \\
\text { - Uso do verbo “fazer, interromper e impedir". }\end{array}$ & 07 \\
\hline TOTAL & & 14 \\
\hline
\end{tabular}

Fonte: Elaborado para esta análise a partir da pesquisa desenvolvida na escola 
Em relação à categoria "Mediação de Conflito", conforme Quadro 6, nenhum dos participantes tinha conhecimento em relação a esta categoria. Os advérbios de negação e de tempo (não e nunca) tiveram exatamente quatorze ocorrências. Porém, de acordo com o Quadro 7, metade dos sujeitos expressaram conhecimento, após a intervenção, em relação à mencionada categoria. Os indicadores que mais apareceram nas amostras foram: resolução de conflitos e mediador (terceira pessoa).

Os dados mostram que os participantes perceberam que a mediação é uma forma de resolver, solucionar os conflitos na qual há a presença de uma terceira pessoa que ajuda as partes a chegarem a um acordo de maneira pacífica.

Gráfico 1 - Comparativo entre o Questionário Inicial e o Final com a evolução dos sujeitos em relação às categorias analisadas

\section{* Questionário Inicial $\times$ Questionário Final \\ Percepção dos alunos (14)}

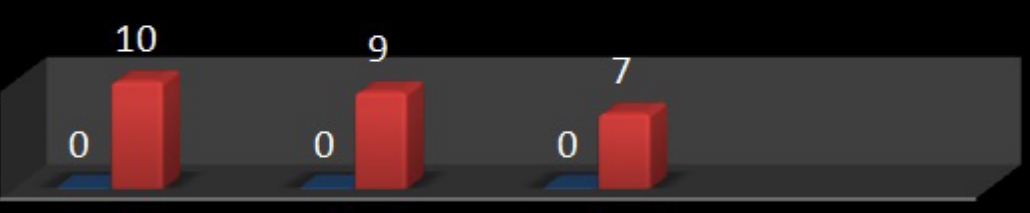

\section{Cultura de Conflito Mediação de \\ Paz \\ Conflito}

Fonte: Elaborado para esta análise a partir da pesquisa desenvolvida na escola.

O Gráfico 1 deixa evidente que nenhum dos participantes conhecia o conceito das categorias analisadas. Porém, com a realização da intervenção ocorreu uma considerável aprendizagem. No que diz respeito à categoria "Cultura de Paz", 70\% dos sujeitos adquiriram conhecimento em relação ao conceito. Já em relação a "Conflito" e "Mediação de Conflito", 65\% e 50\% dos pesquisados, respectivamente, demonstraram aprendizado. A análise e a comparação entre os questionários revelam o quanto foi importante a intervenção para os participantes e, por consequência, para a comunidade escolar.

\section{plurais}




\section{Considerações finais}

Os dados da presente pesquisa revelam que os objetivos propostos foram alcançados, pois a mesma contribuiu para o debate e a percepção dos gestores escolares no que se refere às novas incumbências impostas pela Lei Federal $n^{\circ}$ 13.663/18. A pesquisa, além de trazer referenciais teóricos importantes para que os gestores possam conhecer e conceituar o exposto nos novos dispositivos da lei em questão, também trouxe na prática a realização das novas incumbências.

Além disso, ficou constatado que a lei se trabalhada com conhecimento torna-se efetiva, ou seja, é capaz de promover a paz e prevenir a violência. Concluímos, também, que é possível vivenciar a Cultura de Paz por meio da mediação e restou comprovado pelos resultados que os sujeitos da pesquisa construíram novos conhecimentos acerca da Cultura de Paz, do conflito e da Mediação de Conflitos.

No que se refere ao conceito de "Cultura de Paz" verificamos que houve aumento de percepção dos sujeitos, visto que nas respostas analisadas há a presença da justiça social e da não violência. Também, ficou demonstrado que a maioria dos participantes passou a entender o conflito como algo tanto negativo quanto positivo. Já em relação a Mediação, os dados evidenciaram que os sujeitos perceberam que se trata de uma forma de resolução pacífica de conflitos.

Cabe aqui ressaltar que tanto a educação quanto o homem são seres inacabados, ou seja, sempre estão subordinados ao conhecimento que não se limita de forma alguma. Diante disso, a formação continuada pode e deve ser entendida como parte fundamental do desenvolvimento profissional e deve acontecer ao longo da atuação educacional possibilitando um novo sentido tanto à prática administrativa quanto pedagógica.

A formação continuada está diretamente ligada tanto ao papel do gestor quanto do professor, visto que traz possibilidades de transformação de suas práticas administrativas e pedagógicas e, portanto, possíveis mudanças do contexto escolar. No entanto, para que os educadores, dentre eles os gestores, possam trabalhar com questões relacionadas à cultura de paz, violência, conflito e mediação pacífica de conflitos, objetos do presente estudo, é fundamental a formação continuada para que todos os envolvidos no processo de ensino e aprendizagem possam realmente pôr em prática tais conceitos.

Para além da aprendizagem do conteúdo desenvolvido em sala de aula, a formação traz consigo aspectos relevantes que constituem os educadores e a sua práxis. Sendo assim, formar gestores multiplicadores no que se refere à promoção da Cultura de Paz e conhecedores da Mediação de Conflitos é imperioso. Cabe dizer, ainda, que o gestor sozinho não dará conta de pôr em prática as disposições

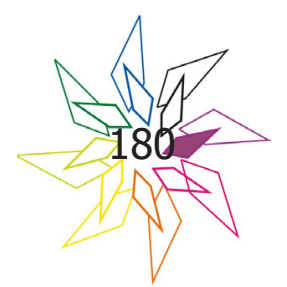


impostas pela lei $\mathrm{N}^{\mathrm{o}} 13.663 / 18$. Dessa forma, o gestor educacional deve ser e atuar como multiplicador, pois assim além de compartilhar o conhecimento e descentralizar as responsabilidades, fará uma gestão democrática na qual todos os envolvidos no processo poderão participar e decidir.

Conclui-se, portanto, que os resultados da pesquisa indicam a importância de incluir cursos de formação e capacitação de gestores educacionais, a fim de inspirar discussões e construções de saberes no que se refere aos novos dispositivos expressos pela lei. Além disso, são fundamentais cursos que possibilitem a formação de gestores multiplicadores e Mediadores de Conflito, visto que a mediação é um dos principais instrumentos de promoção da Cultura de Paz.

\section{REFERÊNCIAS}

BARDIN L. Análise de conteúdo. SP: Edições 70, 2011.

BRASIL. Lei $\mathbf{n}^{\mathbf{0}}$ 13.663, de 14 de maio de 2018. Disponível em: <http://www.planalto.gov.br/ ccivil_03/_ato2015-2018/2018/lei/L13663.htm>. Acesso em: 19 de set. 2018.

Lei no 9.394 de 20 de Dezembro de 1996. Lei de Diretrizes e Bases da Educação

Nacional. Disponível em: <www.planalto.gov.br/ccivil_03/Leis/L9394.htm>. Acesso em: 28 jun. 2018.

CALLADO, Carlos Velazquez. Educação para a Paz: promovendo valores humanos na escola através da educação física e dos jogos cooperativos. Santos/SP: Editora Projeto Cooperativa Ltda, 2004.

CHRISPINO, Álvaro; CHRISPINO, Raquel Santos Pereira. Políticas Educacionais de redução da violência: mediação do conflito escolar. São Paulo: Editora Biruta, 2002.

GARCEZ, José Maria Rossani. Negociação, ADRs, Mediação, Conciliação e Arbitragem. 2a edição ampliada. Rio de Janeiro: Lumen Iuris, 2003.

GIL, Antônio Carlos. Métodos e Técnicas de Pesquisa Social. 6. ed. São Paulo: Atlas, 2008.

GUIMARÃES, Marcelo Rezende. Educação para a paz: sentidos e dilemas. Caxias do Sul, RS: Educs, 2005.

MORAES, Roque. Análise de conteúdo. Revista Educação, Porto Alegre, v. 22, n. 37, p. 7-32, 1999. Disponível em: https://edisciplinas.usp.br/pluginfile.php/4125089/mod_resource/content/1/Roque-Moraes_Analise\%20de\%20conteudo-1999.pdf. Acesso em: 20/08/2018.

\section{plurais}


MINAYO, Maria Cecília de Souza. Pesquisa Social: teoria, método e criatividade. Petrópolis: Vozes, 1994.

NOVAES, Luiza Maria Gray. Justiça Pacificadora e Mediação no Judiciário. 2012. $20 f$. Dissertação (Pós-Graduação) - Escola de Magistratura do Estado do Rio de Janeiro, Rio de Janeiro, 2012.

ONU, Declaração e Plano de Ação Sobre uma Cultura de Paz. Resolução A/ RES/ 53/ 243, de 06 de outubro de 1999 da Assembleia Geral da Organização das Nações Unidas. Disponível em: http://www.comitepaz.org.br. Acesso em: 15 set. 2018.

SEBAJE, Alexandre Zacaria. A Mediação Pacífica de Conflitos e a Promoção da Cultura de Paz em uma Escola Pública Estadual de Pelotas. 2020. 148f. Relatório crítico-reflexivo (Mestrado em Educação) - Escola de Educação, Universidade Federal do Pampa, Jaguarão/RS.

Recebido em: 04 de maio de 2020.

Inserido em: 15 de outubro de 2020.

Esta obra está licenciada com uma Licença Creative Commons Atribuição 4.0 Internacional. 